\title{
REYNOLDS NUMBER EFFECTS IN THE FLOW OF A VOČADLO ELECTRORHEOLOGICAL FLUID IN A CURVED GAP
}

\author{
A. WALICKA* ${ }^{*}$ and J. FALICKI \\ University of Zielona Góra, Faculty of Mechanical Engineering \\ ul. Szafrana 4, 65-516 Zielona Góra, POLAND \\ E-mails: A.Walicka@ijame.uz.zgora.pl; J.Falicki@ibem.uz.zgora.pl
}

\begin{abstract}
Many electrorheological fluids (ERFs) as fluids with micro-structure demonstrate a non-Newtonian behaviour. Rheometric measurements indicate that some flows of these fluids may by modelled as the flows of a Vočadlo ER fluid. In this paper, the flow of a Vočadlo fluid - with a fractional index of non-linearity - in a narrow gap between two fixed surfaces of revolution with a common axis of symmetry is considered. The flow is externally pressurized and it is considered with inertia effect. In order to solve this problem the boundary layer equations are used. The Reynolds number effects (the effects of inertia forces) on the pressure distribution are examined by using the method of averaged inertia terms of the momentum equation. Numerical examples of externally pressurized flows in the gap between parallel disks and concentric spherical surfaces are presented.
\end{abstract}

Key words: inertia effects, fixed surfaces of revolution, Vočadlo ER fluid, pressurized flow.

\section{Introduction}

In the late 1930's Winslow [1], an intrepid basement experimentalist, observed an teresting phenomena when dielectric particles suspended in an insulating oil were subject to an electric field. He saw the electrically induced formation of fibrous particle chains aligned with the electric field and, of more interest, Winslow found that the effective viscosity of the suspension could be varied by orders of magnitude by varying the applied electric field. He also observed that the viscosity increased with the square of the magnitude of the applied electric field. This electrorheological response is often referred to as Winslow effects.

Electrorheological fluids (abbreviated to ERFs) have long held promise for use in vibration control and torque transmission devices, based on the characteristic dependence of their viscosity on the applied electric field strength. Since their discovery by Winslow [1] many kinds of organic or inorganic particles and their composites have been used and reported as the ER materials. When the external electric field is imposed to an ERF, it behaves as a viscoplastic fluid (Shulman et al.[2]; Jordan and Show [3]; Dimarogonas and Kollias [4]; Otsubo [5]; Jung and Choi [6]; Kobayashi et al, [7]; Shulman and Nosov [8]; Walicki and Walicka [9-11]), displaying a field-dependent yield shear stress which is widely variable. Without the electric field, the ERF has a reversible and a constant viscosity so that it flows as a Newtonian fluid. Another salient feature of the ERF is that the time required for the variation is very short $(<0.001 \mathrm{sec})$. These attractive characteristics of the ERF provide the possibility of the appearance of new engineering technology (e.g.,: nuclear and space engineering, mechatronics, etc.). Recently, the application of the ERF to rotor-bearing systems has been initiated by Dimarogonas and Kollias [4]; Jung and Choi [6] and developed by Basaravaja et al. [12]; El Wahed [13]; its application to vibration control has been initiated by Lee et al. [14]; Hong et al. [15, 16] and Choi et al. [17].

To describe the rheological behaviour of viscoplastic fluids in complex geometries the Bingham model is used (Shulman et al. [2]; Covey and Stanmore [18]). Recently, the non-linear model of Shulman [19] has been successfully applied (Korobko [20]). The constitutive equation of this model is given as follows:

\footnotetext{
${ }^{*}$ To whom correspondence should be addressed
} 


$$
\tau=\left[\tau_{0}^{l / n}+(\mu \dot{\gamma})^{l / m}\right]^{n}
$$

where $\tau$ is the shear stress, $\tau_{0}$ is the yield shear stress, $\mu$ is the coefficient of plastic viscosity, $\dot{\gamma}$ is the shear strain rate, $n$ and $m$ are the non-linearity indices. By reducing the coefficients in the Shulman equation one can obtain simpler models describing the flow of a viscoplastic fluid. One of these models is a Vočadlo model (Vočadlo and Charles [21])

$$
\tau=\left[\tau_{0}{ }^{1 / n}+\mu \dot{\gamma}\right]^{n}
$$

The most popular model of the ERF is a Bingham model for which $m=n=1$ in Eq.(1). An analysis of many investigations (El Wahed [13]; Shen et al. [22]; Falicki [23]; Esmonde et al. [24]; Sheng and Wen [25]) indicates that other models may be used - such as Casson $(m=n)$, Vočadlo $(m=1)$ and Herschel-Bulkley $(n=1)$ - to describe ERFs flows.

Recently the Herschel-Bulkley model of a viscoplastic fluid is frequently used as the ERF. in the fullness of time Barnes and Walters [26] launched an ample discussion concerning the interpretation of the notion: yield stress; this discussion was summarized in the paper by Barnes [27]. Reflecting this discussion and also viewpoints presented by Corradini and Peleg [28] it seems that the Vočadlo model better corresponds to reality than the Herschel-Bulkley model; the reasons are as follows:

- functional arrangement gives better possibility to derive an analytical solution for a given problem;

- flow curve shear stress $\tau$ versus shear rate $\dot{\gamma}$ does not exhibit a nearly infinite slope at $\dot{\gamma}=0$ as in the case of the Herschel-Bulkley model but attains a finite value (see Fig.1).

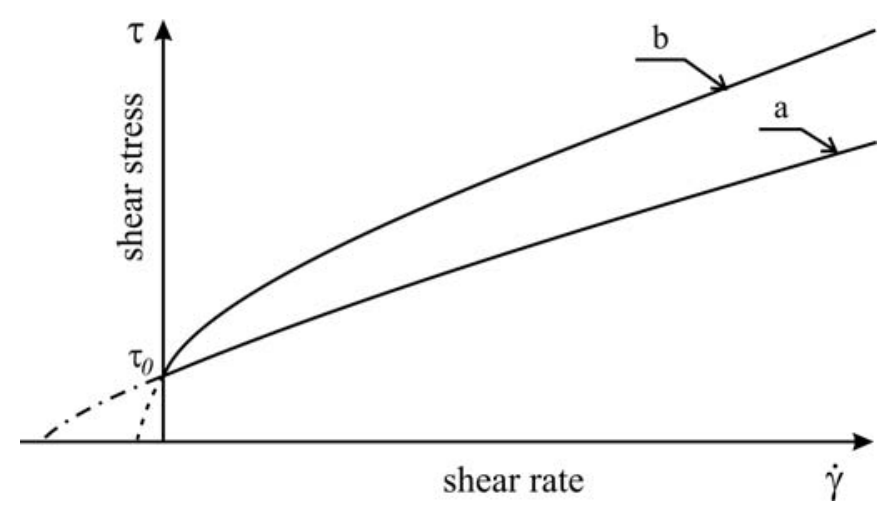

Fig.1. Flow curves for Vočadlo and Herschel-Bulkley fluids:

a) Vočadlo fluid (finite slope at $\dot{\gamma}=0$ ),

b) Herschel-Bulkley fluid (nearly infinite slope at $\dot{\gamma}=0$ ).

The yield shear stress for the ERF varies with respect to the electric field. According to the experimental results reported in (Shulman et al. [2], Jordan and Show [3], Otsubo [5], Shulman and Nosov [8], Shen et al. [22], Sheng and Wen [25], Qiao and Zhao [29], Wunderlich and Brunn [30], Abu-Jdayil et al. [31]), the relation between the yield shear stress $\tau_{0}$ and the electric field strength $\boldsymbol{E}$ is given as follows:

$$
\tau_{0}(E)=\alpha\left(\frac{U}{2 h}\right)^{\beta}
$$


where $E$ is the value of the vector $\boldsymbol{E}$ but $U$ and $2 h$ are the applied voltage and the film thickness, respectively. Both parameters $\alpha$ and $\beta$ are the experimental constants of which the range of the exponent $\beta$ is 1 to 2.4 .

Other experimental data (Whittle et al. [32]) suggest that the yield shear stress for some ERFs follows:

$$
\tau_{0}(E)=\alpha_{1}\left(\frac{U}{2 h}\right)+\alpha_{2}\left(\frac{U}{2 h}\right)^{2}
$$

where $\alpha_{1}$ and $\alpha_{2}$ are constants; for relatively high field strengths a simpler formula may be used:

$$
\tau_{0}(E)=\alpha\left(\frac{U}{2 h}\right)^{2}
$$

where $\alpha$ is an experimental constant.

This paper deals with a laminar flow ERFs modelled as a flow of the Vočadlo fluid - with a fractional index of non-linearity (Vočadlo and Charles [21]) - in the gap modelled as a narrow space between two surfaces of revolution shown in Fig.2. Using the method of averaged inertia (Walicka [33]) and the lubrication approximation theory (Falicki [23], Walicka [34]) the influence of inertia terms of the equations of motion and viscoplastic behaviour parameters on the pressure distribution is analysed.

\section{Equations of motion of an ERF}

The three-dimensional form of the constitutive equation of the Vočadlo model follows (Walicka [33, 34])

$$
\boldsymbol{T}=-p \boldsymbol{1}+M \boldsymbol{A}_{l}, \quad M=\left[\tau_{0}{ }^{l / n}+\mu A\right]^{n} A^{-1} \quad A=\left[\frac{1}{2} \operatorname{tr}\left(\boldsymbol{A}_{l}^{2}\right)\right]^{1 / 2}
$$

where 1 is the unit tensor, $p$ is the pressure, $A$ is second invariant of the stretching tensor $\boldsymbol{A}_{I}$ (the first RivlinEricksen tensor) defined by

$$
\boldsymbol{A}_{1}=\boldsymbol{L}+\boldsymbol{L}^{T}, \quad \boldsymbol{L}=\operatorname{grad} \mathbf{v}
$$

and $\mathbf{v}$ is velocity vector, but $T$ denotes the transposition.

The general equations of motion of the Vočadlo fluid have the following forms:

- equation of continuity

$$
\operatorname{div} \mathbf{v}=0
$$

- equation of momentum

$$
\rho \frac{d \mathbf{v}}{d t}=\operatorname{div} \boldsymbol{T}
$$

or

$$
\rho \frac{d \mathbf{v}}{d t}=-\nabla p+\operatorname{div} \boldsymbol{\Lambda}
$$

where

$$
\Lambda=M A_{l} .
$$


Let us consider the Vočadlo ERF flow in a clearance between fixed surfaces of revolution. The flow configuration is shown in Fig.2. The surfaces of revolution are defined by function $R(x)$ which denotes the radius of the median between the surfaces, plus function $h(x)$ which denotes the distance to each surfaces from the median, measured along a normal to the median. An intrinsic curvilinear orthogonal coordinate system $x, \vartheta, y$ is also depicted in Fig.2.

The physical parameters of the ERF flow are the velocity components $v_{x}, v_{y}$, pressure $p$ and electric field $E$ whose vector $\boldsymbol{E}$ is normal to the median. With regard to the axial symmetry of the flow these parameters are not dependent on the angle $\vartheta$.

The assumption typical for the flow in a narrow gap (Basavaraja et al. [12]; Dimarogonas and Kollias [4], Falicki [23], Walicka [33-35])

$$
h(x)<<R(x)
$$

can be used to make order-of-magnitude arguments for Eqs $(2.3) \div(2.6)$.

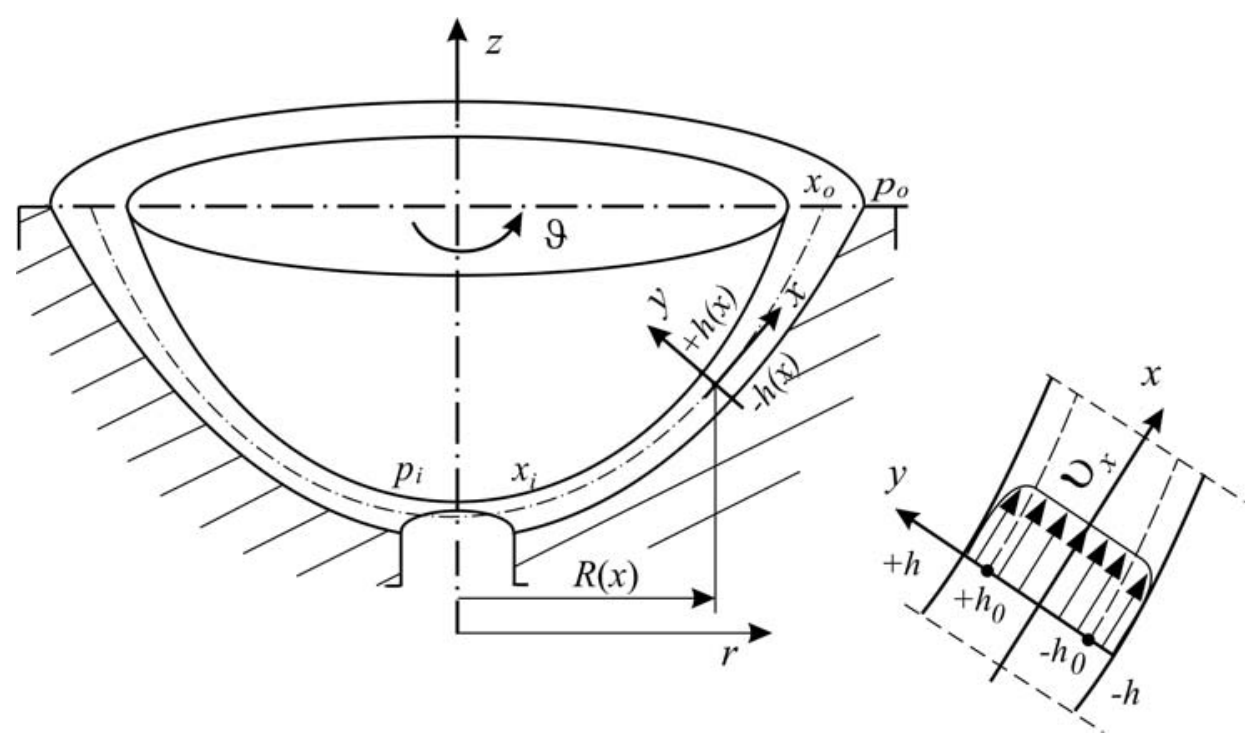

Fig.2. The geometry of a curvilinear gap between two surfaces of revolution.

A further simplification comes by noting that - in accordance to the lubrication approximation - the most important changes in an annular channel occur in the normal (to the channel median) direction. This leads to the assumption that the flow is nearly parallel to the surfaces bounding the gap, so that

$$
v_{y}<<v_{x}, \quad \frac{\partial}{\partial x}<<\frac{\partial}{\partial y}
$$

in an intrinsic coordinate system.

If some asymptotic transformations are made, the same as in (Walicka [33, 34], Falicki [23]), these equations can be reduced to a simpler form

$$
\begin{aligned}
& \frac{1}{R} \frac{\partial\left(R v_{x}\right)}{\partial x}+\frac{\partial v_{y}}{\partial y}=0 \\
& \rho\left(v_{x} \frac{\partial v_{x}}{\partial x}+v_{y} \frac{\partial v_{x}}{\partial y}\right)=-\frac{d p}{d x}+\frac{\partial T_{y x}}{\partial y},
\end{aligned}
$$


where $\quad T_{y x}=S\left[\tau_{0}^{\frac{1}{n}}+\left(\mu\left|\frac{\partial v_{x}}{\partial y}\right|\right)\right]^{n}, \quad \tau_{0}(x)=\alpha\left[\frac{U(x)}{2 h(x)}\right]^{\beta}$

and $S=\operatorname{sgn}\left(\frac{d v_{x}}{d y}\right)$. The signum (sgn) function takes on the value +1 for a positive argument and -1 for a negative argument.

The order-of-magnitude arguments showed that

$$
p=p(x)
$$

is a function of $x$ only.

For a majority of ERFs, greases, molten polymers and mush metals the values of a yield shear stress are contained in the limits: $O(1) \leq \tau_{0} \leq 0(3)$, where $O(\alpha) \sim 10^{\alpha}$ and denotes the order of magnitude, but the exponent $n$ is an integer or fractional number (Vočadlo and Charles [21], Roussel [36], Falicki [23]).

In the flow of a fluid with the yield shear stress there exists a quasi-solid core flow bounded by surfaces lying at

$$
|y|=h_{0} \quad \text { for which the shear stresses are } \quad T_{y x}=S \tau_{0} .
$$

Combining expressions (2.9) and (2.11) one obtains the boundary conditions on liquid surfaces of the core flow as

$$
\frac{\partial v_{x}}{\partial y}=0 \quad \text { for } \quad y= \pm h_{0}
$$

The boundary conditions on solid surfaces are stated as follows

$$
\mathrm{v}_{x}=\mathrm{v}_{y}=0 \quad \text { for } \quad y= \pm h .
$$

On the median line there is also

$$
\frac{\partial v_{x}}{\partial y}=0 \quad \text { for } \quad y=0 \quad \text { and hence } \quad\left|T_{y x}\right|=0 \quad \text { for } \quad y=0
$$

Moreover, in the inlet and the outlet of the clearance conditions for the pressure can be written in the form:

$$
p\left(x_{i}\right)=p_{i}, \quad p\left(x_{o}\right)=p_{o} .
$$

where $x_{i}$ denotes the inlet coordinate and $x_{o}$ - outlet coordinate.

\section{Solution to the equation of motion}

Taking into account Eq.(2.7) one can rearrange Eq.(2.8) writing it in the form

$$
\rho\left(\frac{1}{R} \frac{\partial\left(R v_{x}^{2}\right)}{\partial x}+\frac{\partial}{\partial y}\left(v_{x} v_{y}\right)\right)=-\frac{d p}{d x}+\frac{\partial}{\partial y}\left(S\left[\frac{\frac{1}{n}}{\tau_{0}}+\mu\left|\frac{\partial v_{x}}{\partial y}\right|\right]^{n}\right) .
$$


Then, averaging the left-hand side of Eq.(2.16) across the gap thickness and taking into account the boundary conditions (2.13), we obtain the following equation

$$
\frac{\partial}{\partial y}\left(S\left[\frac{1}{\tau_{0}^{n}}+\mu\left|\frac{\partial v_{x}}{\partial y}\right|\right]^{n}\right)=f(x)
$$

where $f(x)$ is defined as

$$
f(x)=\frac{d p}{d x}+\frac{\rho}{R h} \frac{\partial}{\partial x} R \int_{0}^{h} v_{x}^{2} d y .
$$

Integrating Eq. (2.17) we get (Falicki [23], Walicka, [33-35]):

- for a shear flow

$$
\mathrm{v}_{x s}=\frac{n h^{\frac{n+1}{n}}}{(n+1) \mu}(-f)^{\frac{1}{n}}\left[1-\left(\frac{y}{h}\right)^{\frac{n+1}{n}}-\frac{n+1}{n}\left(\frac{h_{0}}{h}\right)^{\frac{1}{n}}\left(1-\frac{y}{h}\right)\right]
$$

where $\left|T_{y x}\right|>\tau_{0} \quad$ or $\quad|y|>h_{0}$;

- for a core flow

$$
\mathrm{v}_{x c}=\frac{n h^{\frac{n+1}{n}}}{(n+1) \mu}(-f)^{\frac{1}{n}}\left[1-\left(\frac{h_{0}}{h}\right)^{\frac{n+1}{n}}-\frac{n+1}{n}\left(\frac{h_{0}}{h}\right)^{\frac{1}{n}}\left(1-\frac{h_{0}}{h}\right)\right]
$$

where $\left|T_{y x}\right| \leq \tau_{0} \quad$ or $\quad|y| \leq h_{0}$.

The flow rate $Q$ is defined as

$$
Q=2 \pi R \int_{-h}^{+h} \mathrm{v}_{x} d y=4 \pi R\left(\int_{0}^{h_{0}} \mathrm{v}_{x c} d y+\int_{h_{0}}^{h} \mathrm{v}_{x s} d y\right) .
$$

Using here expressions (2.19) and (2.20) we obtain

$$
Q=\frac{4 \pi n R h_{0}^{\frac{2 n+1}{n}}}{\mu}(-f)^{\frac{1}{n}}\left\{\frac{1}{2 n+1}\left[\left(\frac{h}{h_{0}}\right)^{\frac{2 n+1}{n}}-1\right]-\frac{1}{2 n}\left[\left(\frac{h}{h_{0}}\right)^{2}-1\right]\right\}
$$

the equation with an unknown quantity $f$. 
Introducing the following notations

$$
K=\frac{\mu Q}{4 \pi R h^{2} \tau_{0}^{\frac{1}{n}}}, \quad X=\left(-\frac{h f}{\tau_{0}}\right)=\frac{h}{h_{0}}
$$

we will obtain the equation

$$
\frac{n}{2 n+1} X^{\frac{2 n+1}{n}}-\frac{1}{2}(2 K+1) X^{2}+\frac{1}{2(2 n+1)}=0
$$

which is characteristic to the flow of the Vočadlo fluid in the gap between two fixed surfaces of revolution. Its analytical solutions $X_{s}$ exist only for large and mean values of $K \quad(\geq 0.1)$ and for small values of $K$ $(\leq 0.05)$ and they have the form (Falicki [23], Walicka, [33-35])

$$
X_{s}=\left[\frac{2 n+1}{2 n}(1+2 K)\right]^{n}, \quad X_{s}=1+(2 n K)^{\frac{1}{2}}
$$

To determine the pressure distribution let us turn to expression (2.18). Rearranging it we get:

$$
\frac{d p}{d x}=f(x)-\frac{\rho}{R h} \frac{\partial}{\partial x} R \int_{0}^{h} v_{x}^{2} d y .
$$

Taking into account expressions (2.25) and integrating Eq.(2.26) we will find

$$
p(x)=p_{o}+\left[S(x)-S_{o}\right]+\left[D(x)-D_{o}\right], \quad S_{o}=S\left[x_{o}\right], \quad D_{o}=D\left[x_{o}\right] .
$$

The functions $S(x)$ and $D(x)$ are given by expressions

$$
S(x)=-\int \tau_{0} \frac{X_{s}}{h} d x, \quad D(x)=-\rho \int \frac{1}{R h} \frac{\partial}{\partial x}(R V) d x
$$

where

$$
\begin{aligned}
& V=\frac{\tau_{0}^{\frac{2}{n}} h^{3}}{\mu^{2}}\left\{\frac{2 n^{2}}{(2 n+1)(3 n+2)} X_{s}^{\frac{2}{n}}-\frac{n(4 n+1)}{(2 n+1)(3 n+1)} X_{s}^{\frac{1}{n}}+\frac{1}{3}+\right. \\
& \left.+\frac{n}{(n+1)(2 n+1)} X_{s}^{-\frac{2 n-1}{n}}-\frac{1}{2 n+1} X_{s}^{-2}+\frac{2(5 n+2)}{3(n+1)(3 n+1)(3 n+2)} X_{s}^{-3}\right\} .
\end{aligned}
$$

Note that the final forms of $S(x)$ and $D(x)$ depend - for $U(x)=U_{o}=$ const - on the values of $K$ and $n$ :

- for large and mean values of $K$ and exponent $n$ being a natural number we have 


$$
\begin{aligned}
& S(x)=-\alpha\left(\frac{U_{o}}{2}\right)^{\beta}\left(\frac{2 n+1}{2 n}\right)^{n} \sum_{i=0}^{n} C_{n}^{i}\left(2 A_{n}\right)^{i} J_{(n)}^{(i ; \beta)}(x), \\
& D(x)=-\frac{\rho \alpha^{\frac{2}{n}}}{\mu^{2}(3 n+1)(3 n+2)}\left(\frac{U_{o}}{2}\right)^{\frac{2 \beta}{n}}\left[2(2 n+1)(3 n+2) A_{n}^{2} I_{(n)}^{(2 ; \beta)}(x)+\right. \\
& \left.-n A_{n} I_{(n)}^{(1 ; \beta)}(x)+\frac{1}{6} I_{(n)}^{(0 ; \beta)}(x)\right]
\end{aligned}
$$

where

$$
\begin{aligned}
& A_{n}=\frac{\mu Q}{2^{2-\frac{\beta}{n}} \pi \alpha^{\frac{1}{n}} U_{o}^{\frac{\beta}{n}}}, \quad J_{(n)}^{(\alpha ; \beta)}(x)=\int R^{-\alpha} h^{-(1+2 \alpha)-\left(1-\frac{\alpha}{n}\right) \beta} d x, \\
& I_{(n)}^{(\alpha ; \beta)}(x)=\int \frac{1}{R h}\left[R^{1-\alpha} h^{3-2 \alpha-(2-\alpha) \frac{\beta}{n}}\right]^{\prime} d x, \quad C_{\beta}^{\alpha}=\frac{\beta !}{\alpha !(\beta-\alpha) !},
\end{aligned}
$$

- for large and mean values of $K$ and exponent $n$ being a rational number the final form of $D(x)$ is similar and $S(x)$ takes the form

$$
S(x)=-\alpha\left(\frac{U_{o}}{2}\right)^{\beta}\left(\frac{2 n+1}{2 n}\right)^{n} \sum_{i=0}^{\infty} \Gamma_{n}^{i}\left(2 A_{n}\right)^{n-i} J_{(n)}^{(n-i ; \beta)}(x),
$$

where

$$
\Gamma_{\beta}^{\alpha}=\frac{1}{\alpha !} \prod_{k=1}^{\alpha}(\beta+1-k), \quad \Gamma_{\beta}^{0}=1
$$

- $\quad$ for small values of $K$ we have

$$
\begin{aligned}
& S(x)=-\alpha\left(\frac{U_{o}}{2}\right)^{\beta}\left[J_{(n)}^{(0 ; \beta)}(x)+\left(2 n A_{n}\right)^{\frac{1}{2}} J_{(n)}^{\left(\frac{1}{2} ; \beta\right)}(x)\right] \\
& D(x)=-\frac{\rho \alpha^{\frac{2}{n}}}{\mu^{2}}\left(\frac{U_{o}}{2}\right)^{\frac{2 \beta}{n}}\left[A_{0}(n) I_{(n)}^{(0 ; \beta)}(x)+A_{1}(n)\left(2 n A_{n}\right)^{\frac{1}{2}} I_{(n)}^{\left(\frac{1}{2} ; \beta\right)}(x)+\right. \\
& \left.+A_{2}(n)\left(2 n A_{n}\right) I_{(n)}^{(1 ; \beta)}(x)+A_{3}(n)\left(2 n A_{n}\right)^{\frac{3}{2}} I_{(n)}^{\left(\frac{3}{2} ; \beta\right)}(x)\right]
\end{aligned}
$$


where

$$
\begin{aligned}
& A_{0}(n)=\left(238.3-214.4 n+72.19 n^{2}-8.559 n^{3}\right) \cdot 10^{-6} \\
& A_{1}(n)=-\left(49.3-36.5 n+9.905 n^{2}-0.9207 n^{3}\right) \cdot 10^{-4} \\
& A_{2}(n)=\left(-73.31+203.3 n-201 n^{2}+95.28 n^{3}-22.03 n^{4}+2 n^{5}\right) \cdot 10^{-3} \\
& A_{3}(n)=(0.04586 n)^{-2,742} \cdot 10^{-5}
\end{aligned}
$$

The prime denotes differentiation with respect to $x$.

For $\tau_{0}(x)=\tau_{0}=$ const (the coefficient $\beta=0$ but $\alpha=\tau_{0}$ ) we have (Falicki [23], Walicka and Falicki [37]):

- for large and mean values of $K$ and exponent $n$ being a natural number

$$
\begin{aligned}
& S(x)=-\tau_{0}\left(\frac{2 n+1}{2 n}\right)^{n} \sum_{i=0}^{n} C_{n}^{i}\left(2 A_{n}\right)^{i} J_{(n)}^{(i)}(x), \\
& D(x)=-\frac{\rho \tau_{0}^{\frac{2}{n}}}{\mu^{2}(3 n+1)(3 n+2)}\left[2(2 n+1)(3 n+1) A_{n}^{2} I_{(I)}^{(2)}(x)+\right. \\
& \left.-n A_{n} I_{(I)}^{(I)}(x)+\frac{1}{6} I_{(I)}^{(0)}(x)\right]
\end{aligned}
$$

where

$$
A_{n}=\frac{\mu Q \tau_{0}^{-\frac{1}{n}}}{4 \pi}, \quad J_{(n)}^{(\alpha ; 0)}(x)=J_{(n)}^{(\alpha)}(x), \quad I_{(n)}^{(j ; 0)}(x)=I_{(n)}^{(j)}(x)
$$

- for large and mean values of $K$ and exponent $n$ being a rational number the final form of $D(x)$ is similar and $S(x)$ takes the form (Falicki [23])

$$
S(x)=-\tau_{0}\left(\frac{2 n+1}{2 n}\right)^{n} \sum_{i=0}^{\infty} \Gamma_{n}^{i}\left(2 A_{n}\right)^{n-i} J_{(n)}^{(n-i)}(x)
$$

- $\quad$ for small values of $K$ there are

$$
S(x)=-\tau_{0}\left[\int \frac{d x}{h}+\left(2 n A_{n}\right)^{\frac{1}{2}} J_{(n)}^{\left(\frac{1}{2}\right)}(x)\right]
$$




$$
\begin{aligned}
& D(x)=-\frac{\rho \tau_{0}^{\frac{2}{n}}}{\mu^{2}}\left[A_{0}(n) I_{(2)}^{(0)}(x)+A_{1}(n)\left(2 n A_{n}\right)^{\frac{1}{2}} I_{(2)}^{(I)}(x)+\right. \\
& \left.+A_{2}(n)\left(2 n A_{n}\right) I_{(2)}^{(2)}(x)+A_{3}(n)\left(2 n A_{n}\right)^{\frac{3}{2}} I_{(2)}^{(3)}(x)\right]
\end{aligned}
$$

where coefficients $A_{i}(n)$ are given by relations (2.37).

\section{Examples of the flows and graphic presentation of some results}

Taking into account the results obtained in the previous section we will present the pressure distribution in the gap of constant thickness between two parallel disks shown in Fig. 3 and between two concentric spherical surfaces shown in Fig.4. To this aim we introduce the following dimensionless parameters:

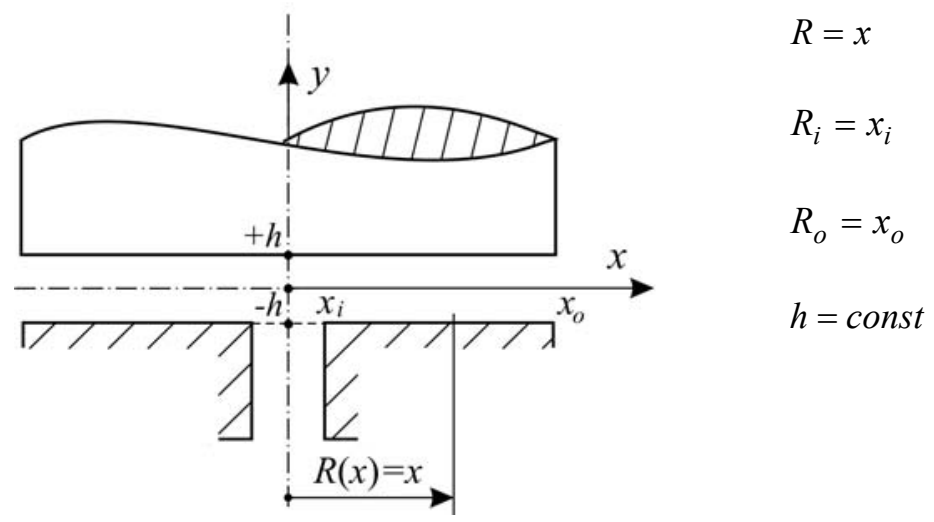

Fig.3. Geometry of a gap between two parallel disks.

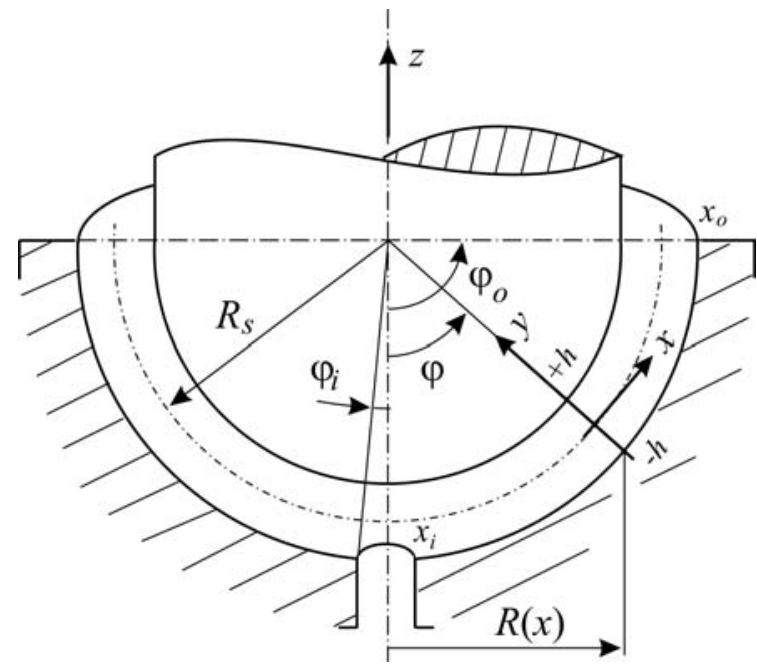

$$
\begin{aligned}
& R=R_{S} \sin \varphi \\
& \varphi=\frac{x}{R_{s}} \\
& R_{i}=R_{S} \sin \varphi_{i} \\
& R_{o}=R_{S} \sin \varphi_{o} \\
& h=\text { const }
\end{aligned}
$$

Fig.4. Geometry of a gap between two concentric spherical surfaces.

for a gap between two parallel disks

$$
\tilde{x}=\frac{x}{R_{o}}, \quad \tilde{R}=\frac{R}{R_{o}}=\tilde{x},
$$


for a gap between two concentric spherical surfaces

$$
\tilde{x}=\varphi, \quad \tilde{R}=\sin \varphi,
$$

and

$$
\tilde{p}=\frac{\rho\left(p-p_{o}\right)(2 h)^{4 n} Q^{2-n}}{(2 \pi)^{2-n} \mu^{2 n} R_{o}^{4-2 n} R_{\lambda}}, \quad R_{\lambda}=\frac{\rho Q^{2-n}}{(2 \pi)^{2-n} \mu^{n} R_{o}^{3-n}(2 h)^{1-2 n}}, \quad K_{S V}=\frac{\frac{2}{n}-2^{\frac{\beta}{n}} Q h^{\frac{\beta}{n}-2}}{\pi \alpha^{\frac{1}{n}} R_{o} U_{o}^{\frac{\beta}{n}}} ;
$$

if $\beta=0$, then $\alpha=\tau_{0}=$ const and $K_{S V}=\frac{\mu Q}{4 \pi R_{o} h^{2} \tau_{0}^{\frac{1}{n}}}$.

For spherical surfaces: $R_{o}=R_{S}$ in all dimensionless parameters.

The nondimensional formula for the pressure distribution in the ER flow of the Vočadlo fluid has the form

$$
\widetilde{p}=\widetilde{S}(\widetilde{x})-\widetilde{S}_{o}+\widetilde{D}(\widetilde{x})-\widetilde{D}_{o}
$$

Note that if $n=1$ all the above formulae represent the Bingham ERF flow.

$R_{\lambda}$ is the modified Reynolds number and $K_{S V}$ is the ER plasticity number (de Saint-Venant ER number). Note that large values of the plasticity number correspond to the flow with small core ( $\operatorname{small} h_{0} / h$ ).

The nondimensional pressure distributions of ERFs are presented in Figs 5-18 for the flows between parallel disks and for the flows between concentric spherical surfaces.

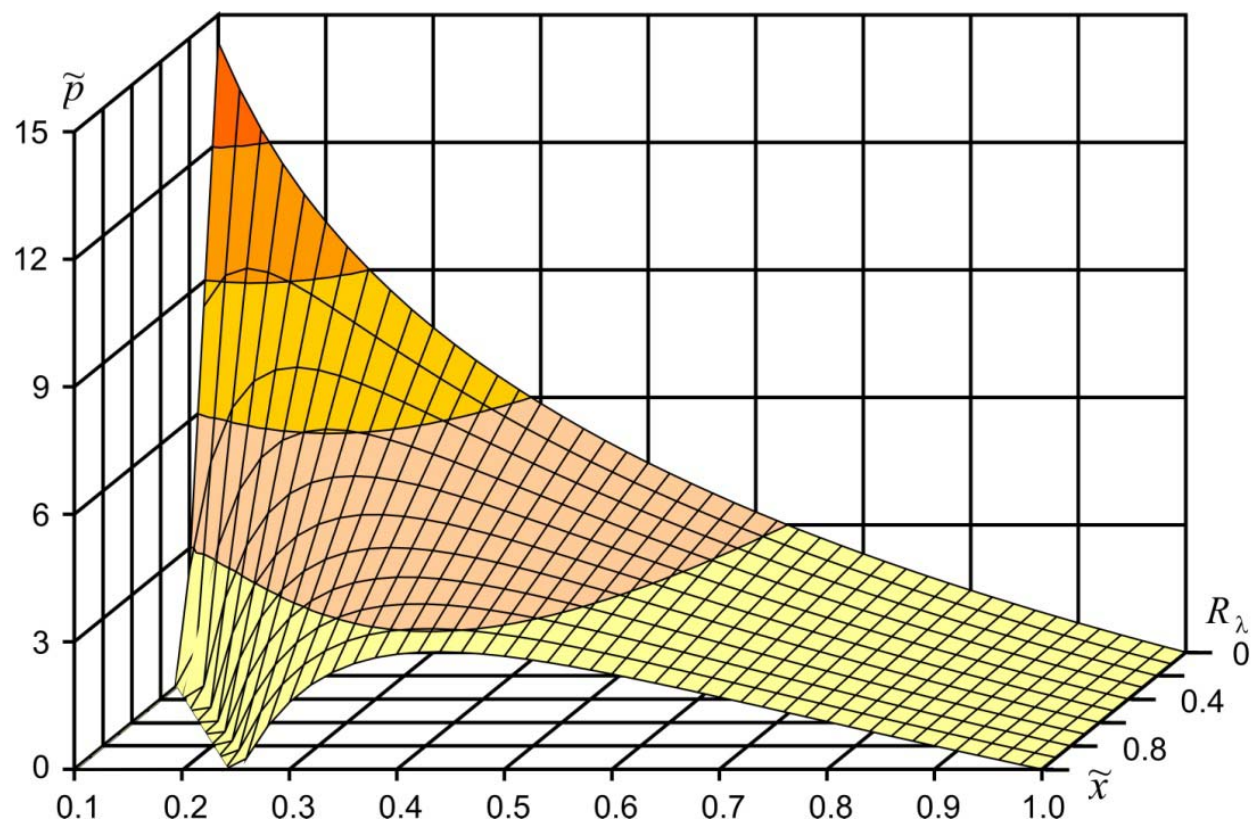

Fig.5. Dimensionless pressure distributions $\widetilde{p}$ for the Vočadlo ERF flow in a gap between parallel disks for different values of $R_{\lambda}$, large value of $K_{S V}=5$ and the value of exponent $n=1$ (the ERF of a Bingham type). 


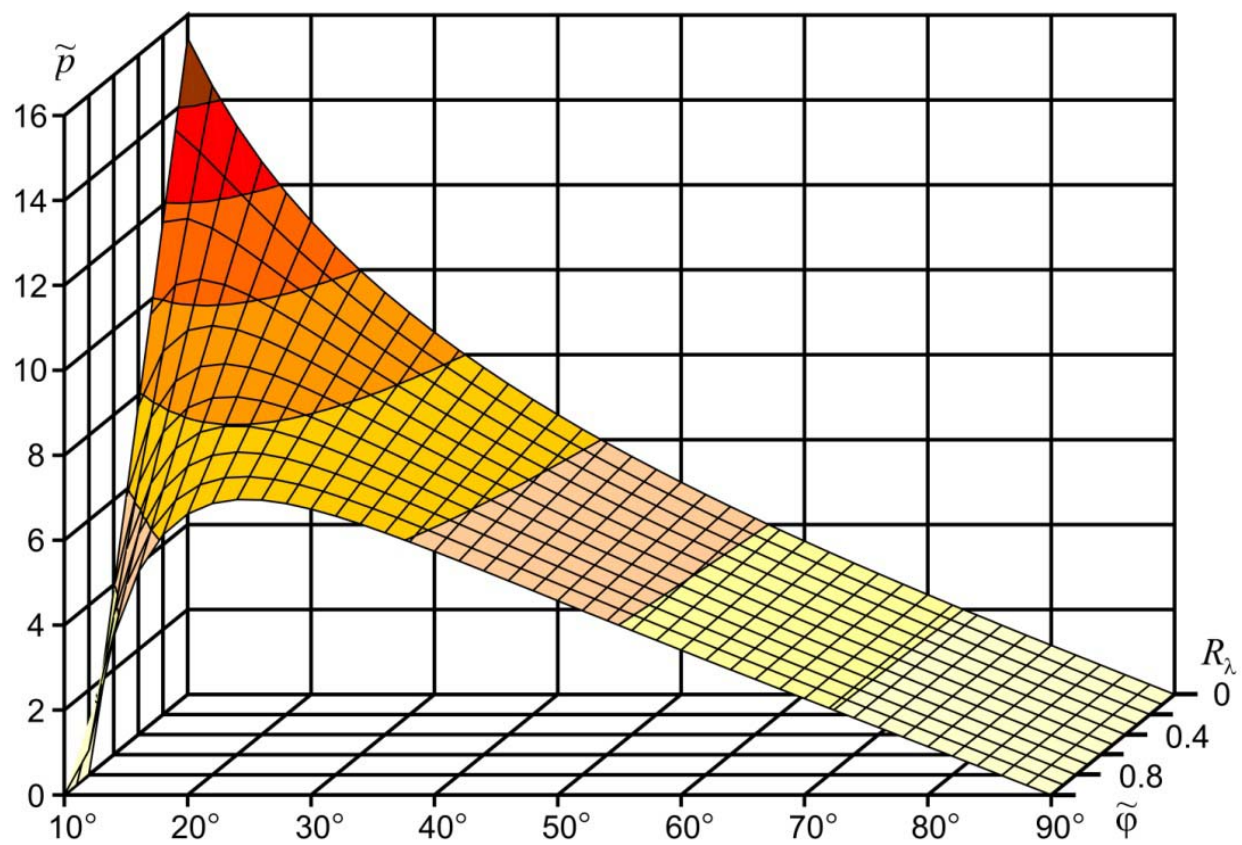

Fig.6. Dimensionless pressure distributions $\widetilde{p}$ for the Bingham ERF flow in a gap between concentric spherical surfaces for different values of $R_{\lambda}$, large value of $K_{S V}=5$ and the value of exponent $n=1$.

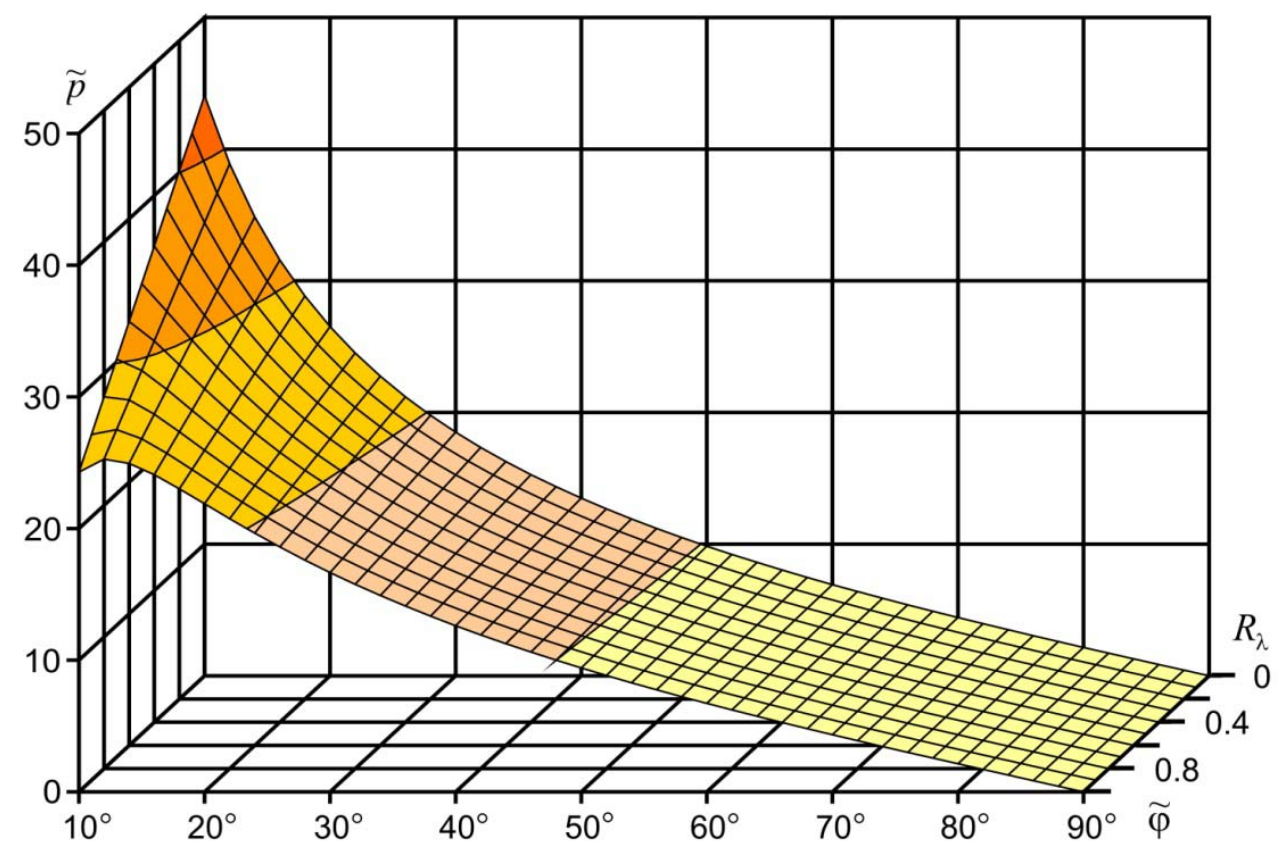

Fig.7. Dimensionless pressure distributions $\widetilde{p}$ for the Vočadlo ERF flow in a gap between parallel disks for different values of $R_{\lambda}$, large value of $K_{S V}=5$ and the value of exponent $n=1.5$. 


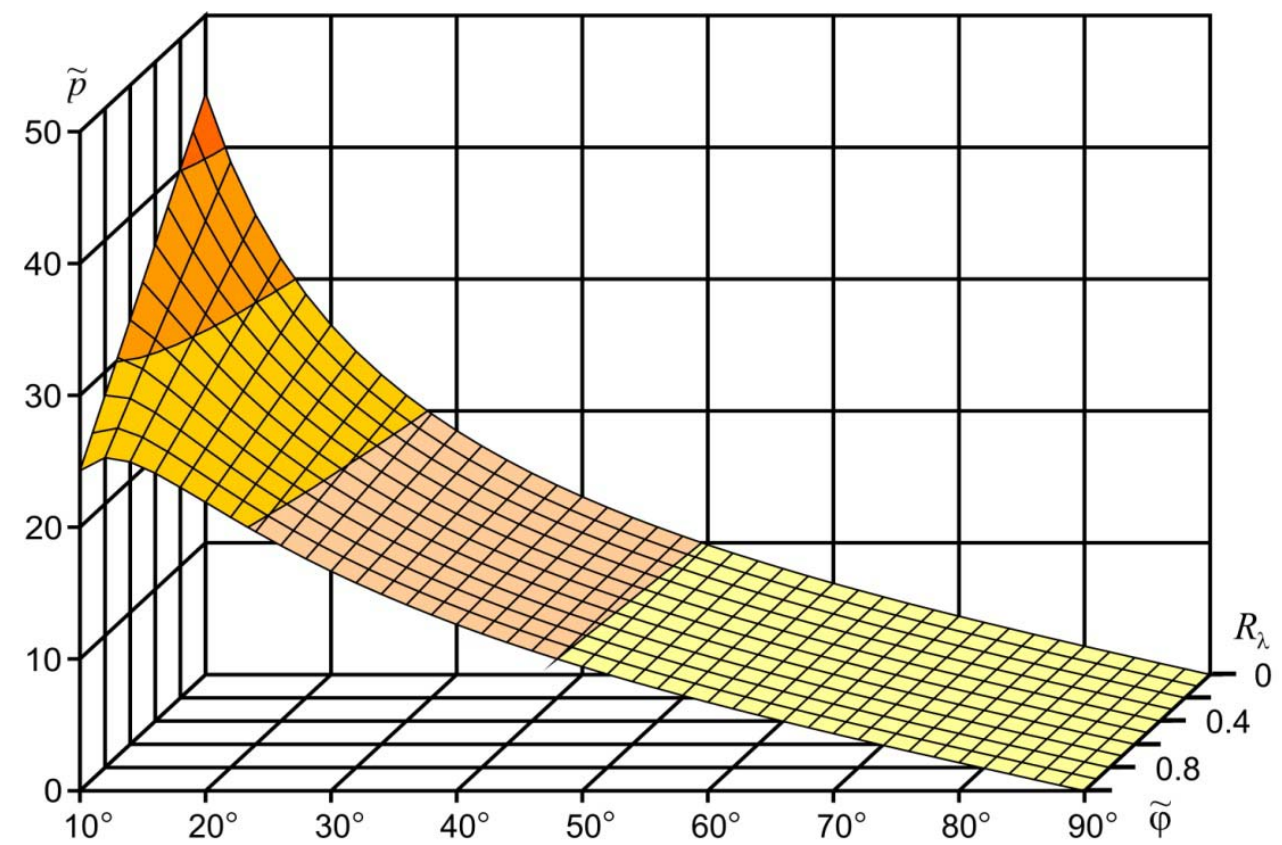

Fig.8. Dimensionless pressure distributions $\widetilde{p}$ for the Vočadlo ERF flow in a gap between concentric spherical surfaces for different values of $R_{\lambda}$, large value of $K_{S V}=5$ and the value of exponent $n=1.5$.

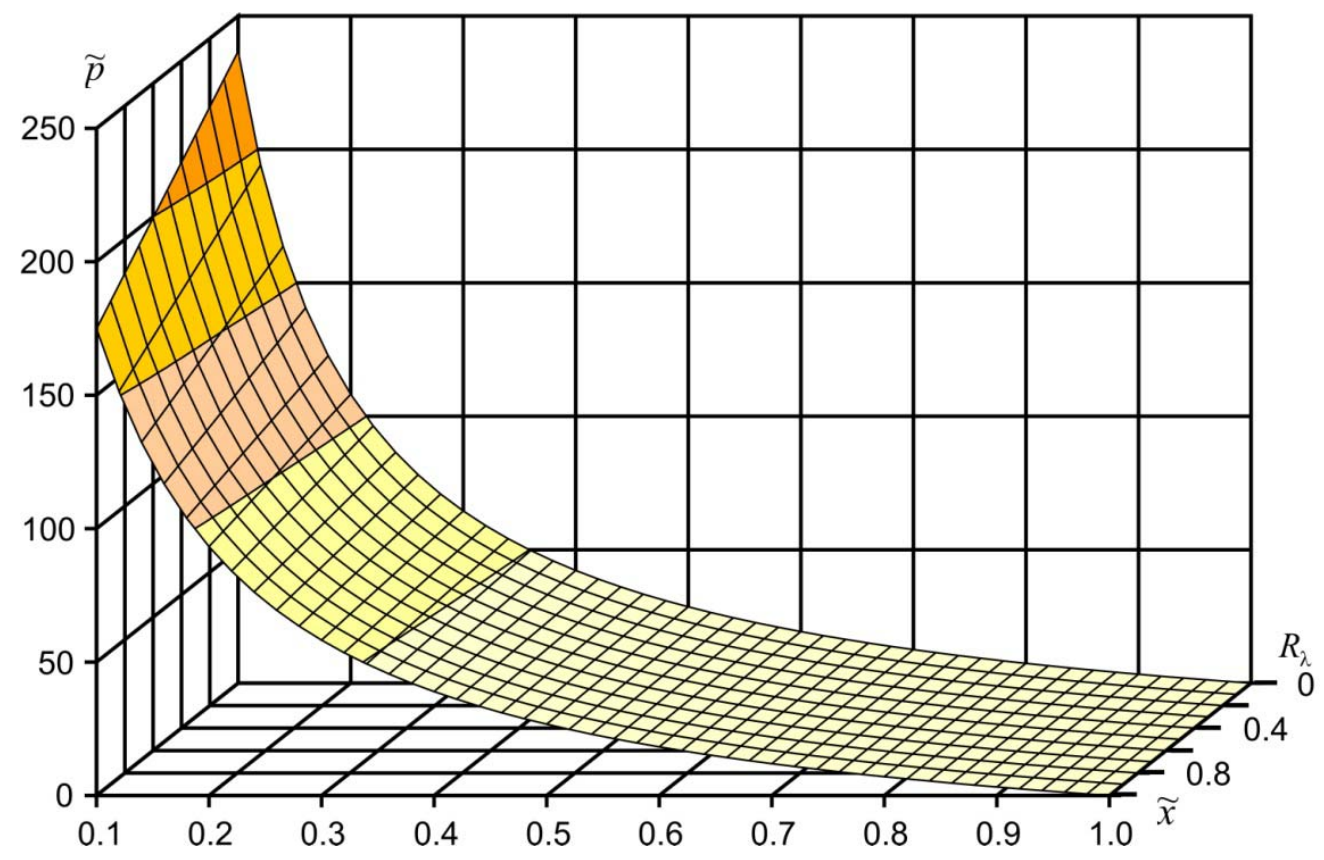

Fig.9. Dimensionless pressure distributions $\widetilde{p}$ for the Vočadlo ERF flow in a gap between parallel disks for different values of $R_{\lambda}$, large value of $K_{S V}=5$ and the value of exponent $n=2$. 


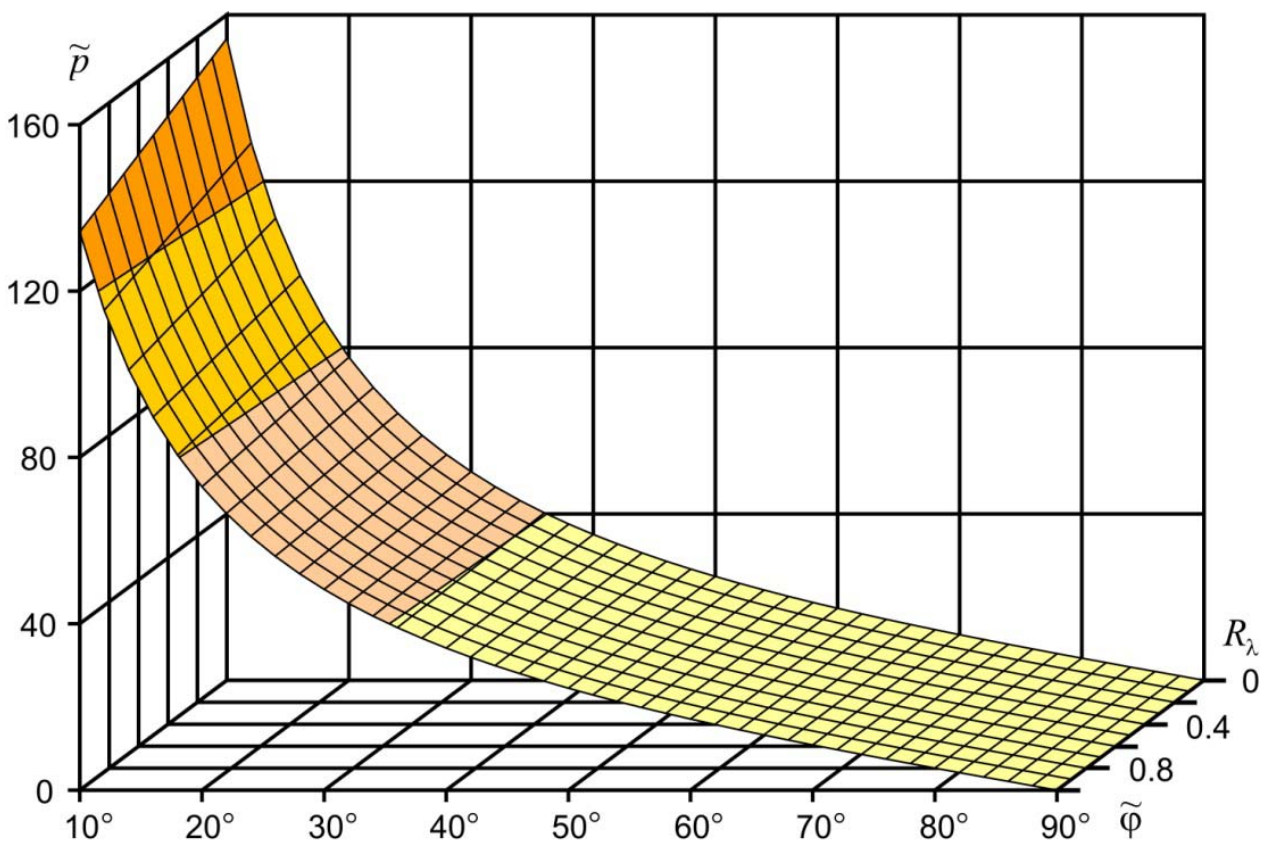

Fig.10. Dimensionless pressure distributions $\widetilde{p}$ for the Vočadlo ERF flow in a gap between concentric spherical surfaces for different values of $R_{\lambda}$, large value of $K_{S V}=5$ and the value of exponent $n=2$.

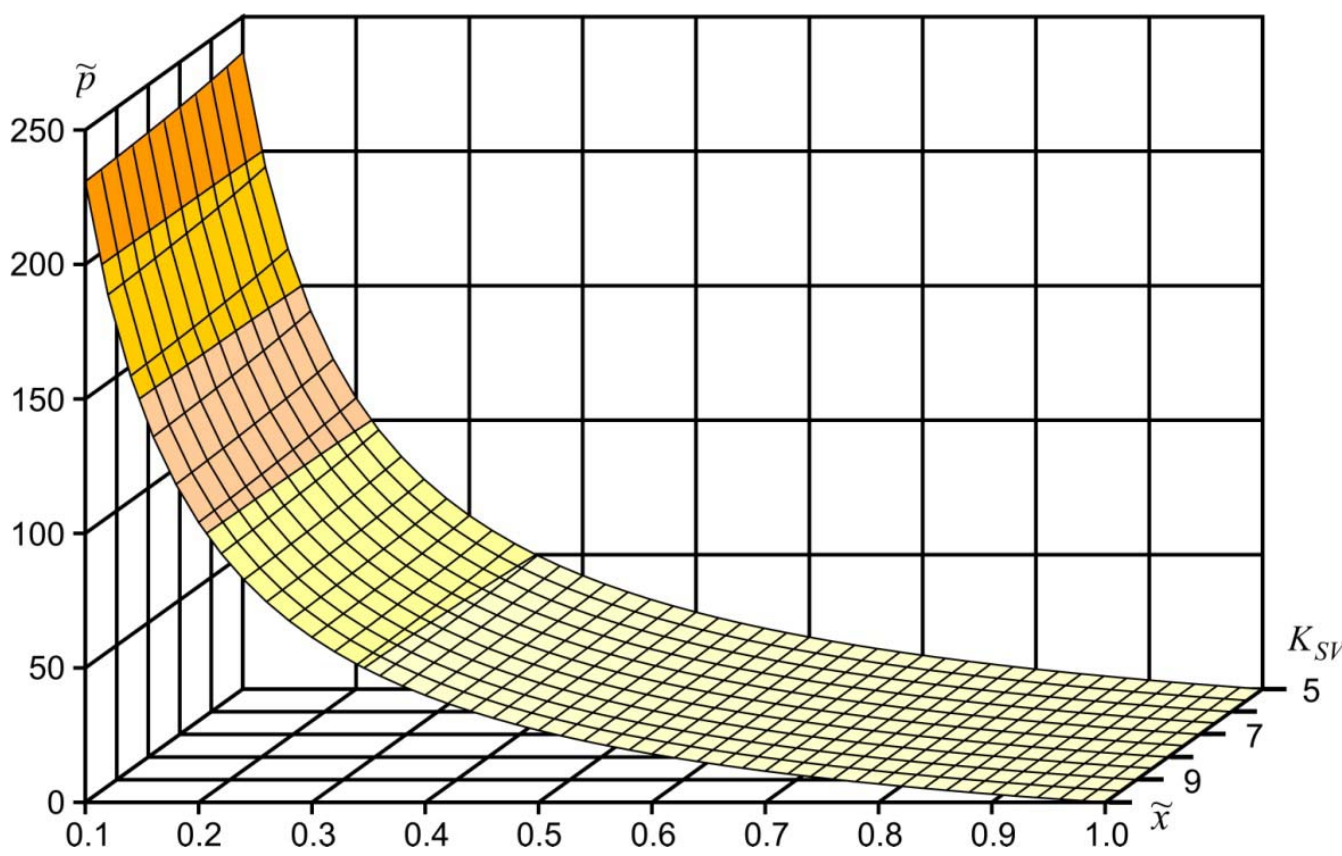

Fig.11. Dimensionless pressure distributions $\widetilde{p}$ for the Vočadlo ERF flow in a gap between parallel disks for different values of $K_{S V}=5 \div 10$, the value of exponent $n=2$ and constant value of $R_{\lambda}=0$. 


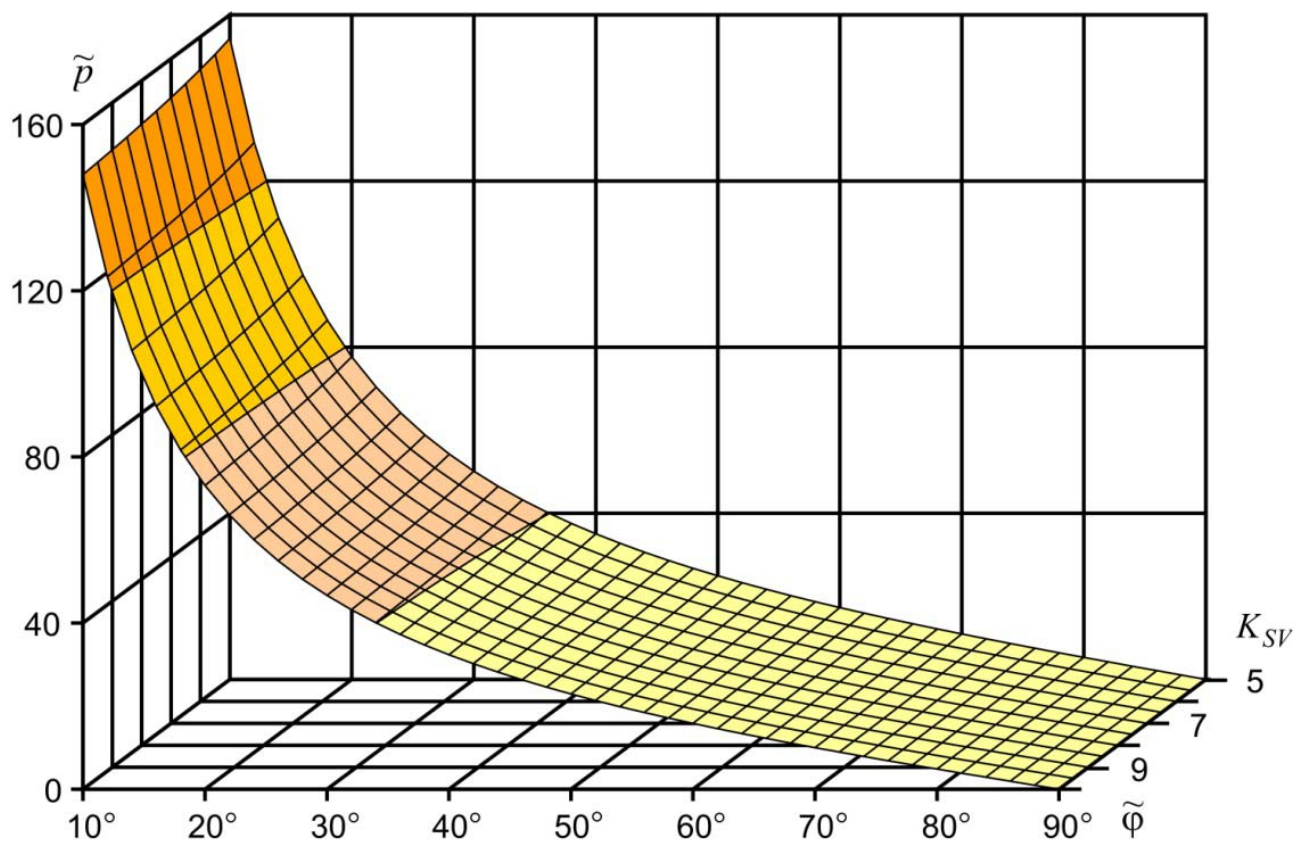

Fig.12. Dimensionless pressure distributions $\widetilde{p}$ for the Vočadlo ERF flow in a gap between concentric spherical surfaces for different values of $K_{S V}=5 \div 10$, the value of exponent $n=2$ and constant value of $R_{\lambda}=0$.

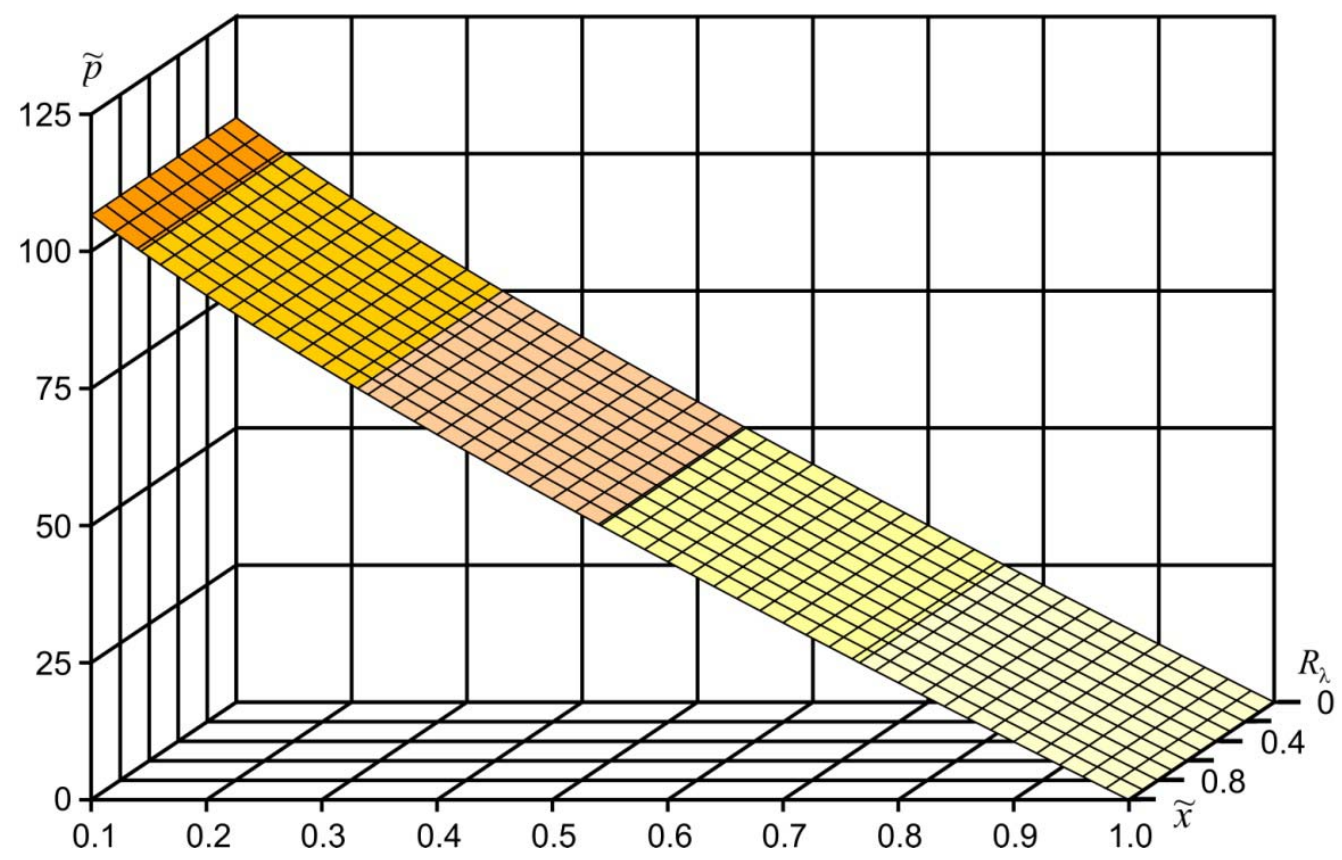

Fig.13. Dimensionless pressure distributions $\widetilde{p}$ for the Vočadlo ERF flow in a gap between parallel disks for different values of $R_{\lambda}=0 \div 1.0$, small value of $K_{S V}=0.05$ and the value of exponent $n=1$ (the ERF of a Bingham type). 


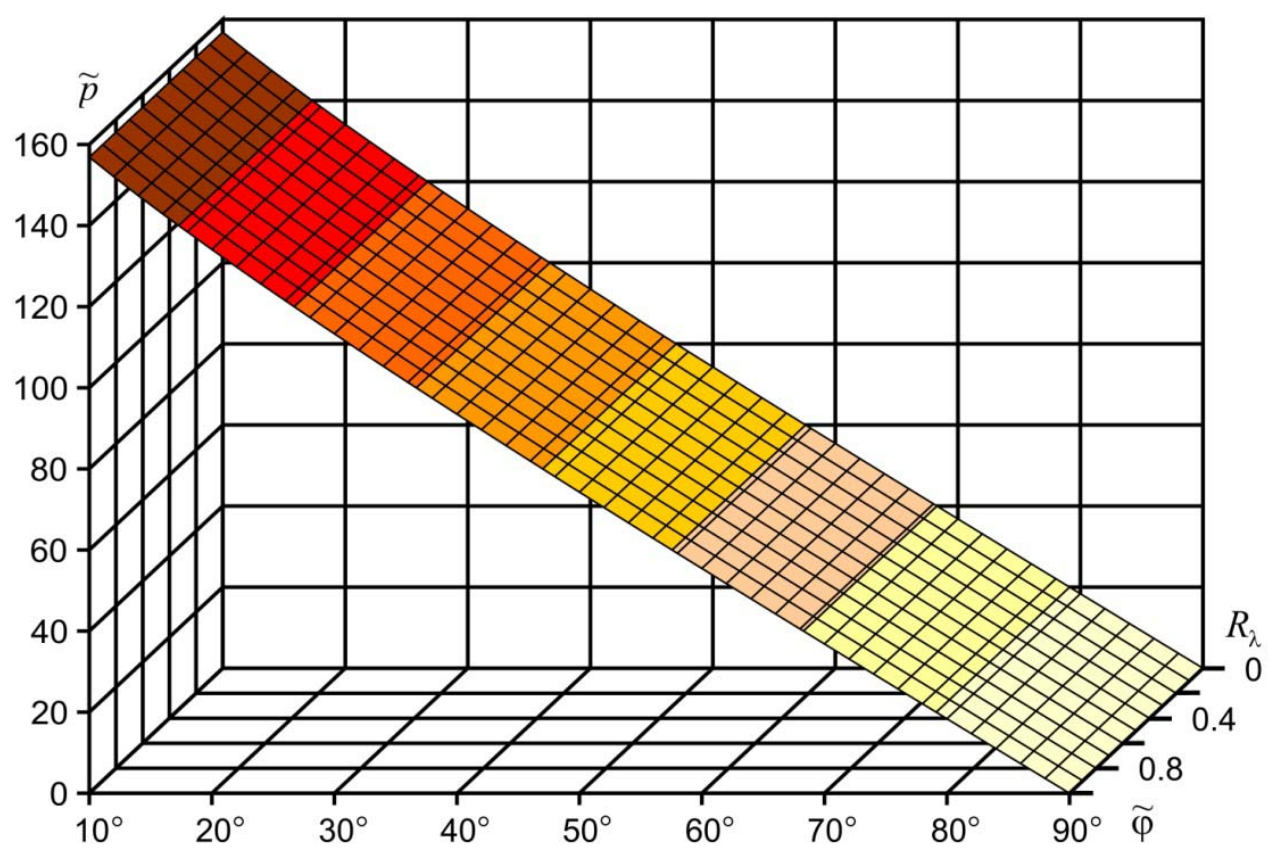

Fig.14. Dimensionless pressure distributions $\widetilde{p}$ for the Bingham ERF flow in a gap between concentric spherical surfaces for different values of $R_{\lambda}=0 \div 1.0$, small value of $K_{S V}=0.05$ and the value of exponent $n=1$.

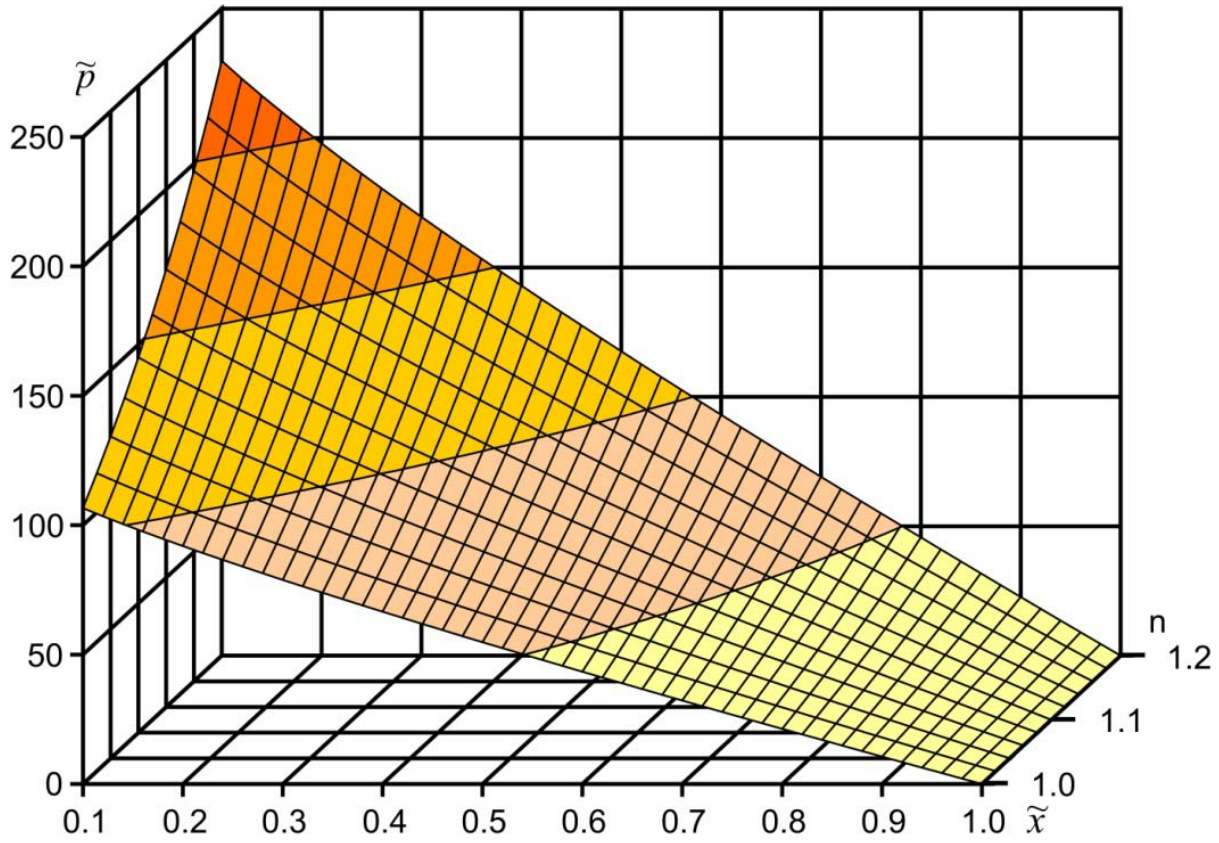

Fig.15. Dimensionless pressure distributions $\widetilde{p}$ for the Vočadlo ERF flow in a gap between parallel disks for different values of exponent $n=1 \div 1.2$, small value of $K_{S V}=0.05$ and constant value $R_{\lambda}=0$. 


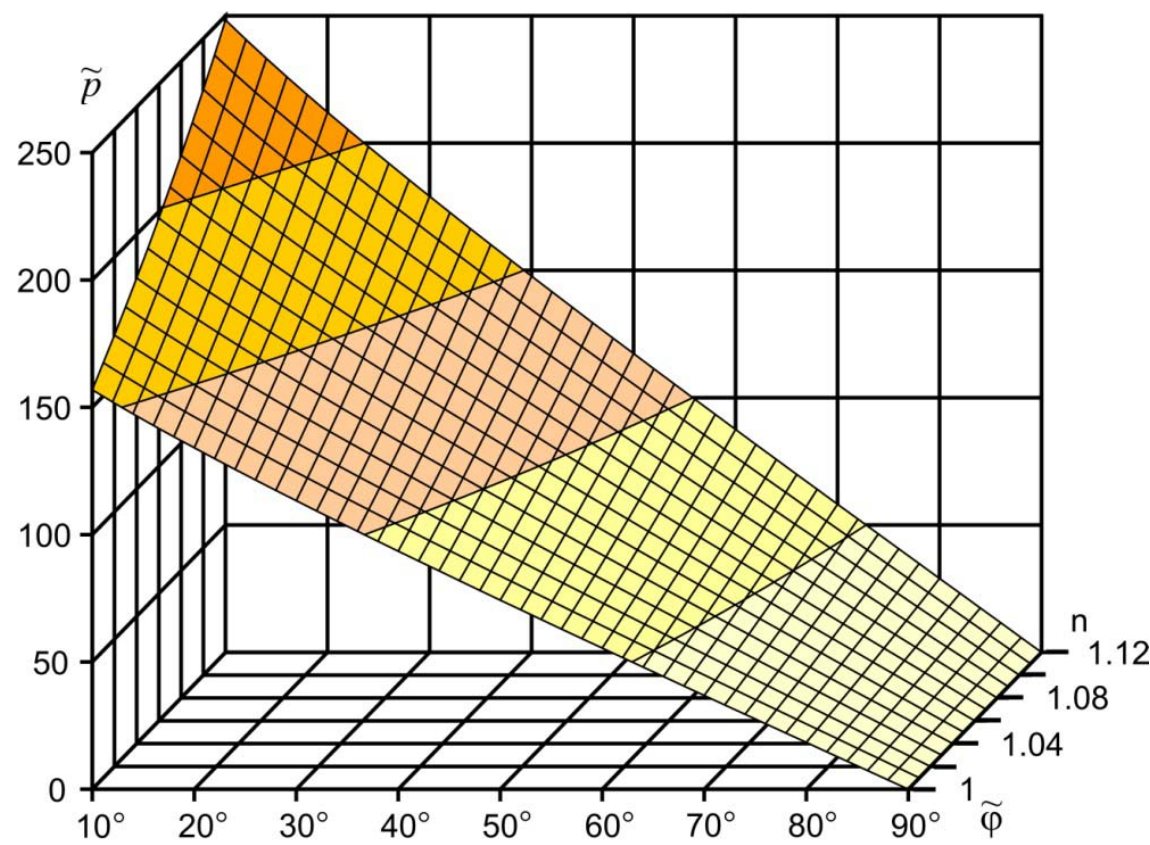

Fig.16. Dimensionless pressure distributions $\widetilde{p}$ for the Vočadlo ERF flow in a gap between concentric spherical surfaces for different values of exponent $n=1 \div 1.12$, small value of $K_{S V}=0.05$ and constant value $R_{\lambda}=0$.

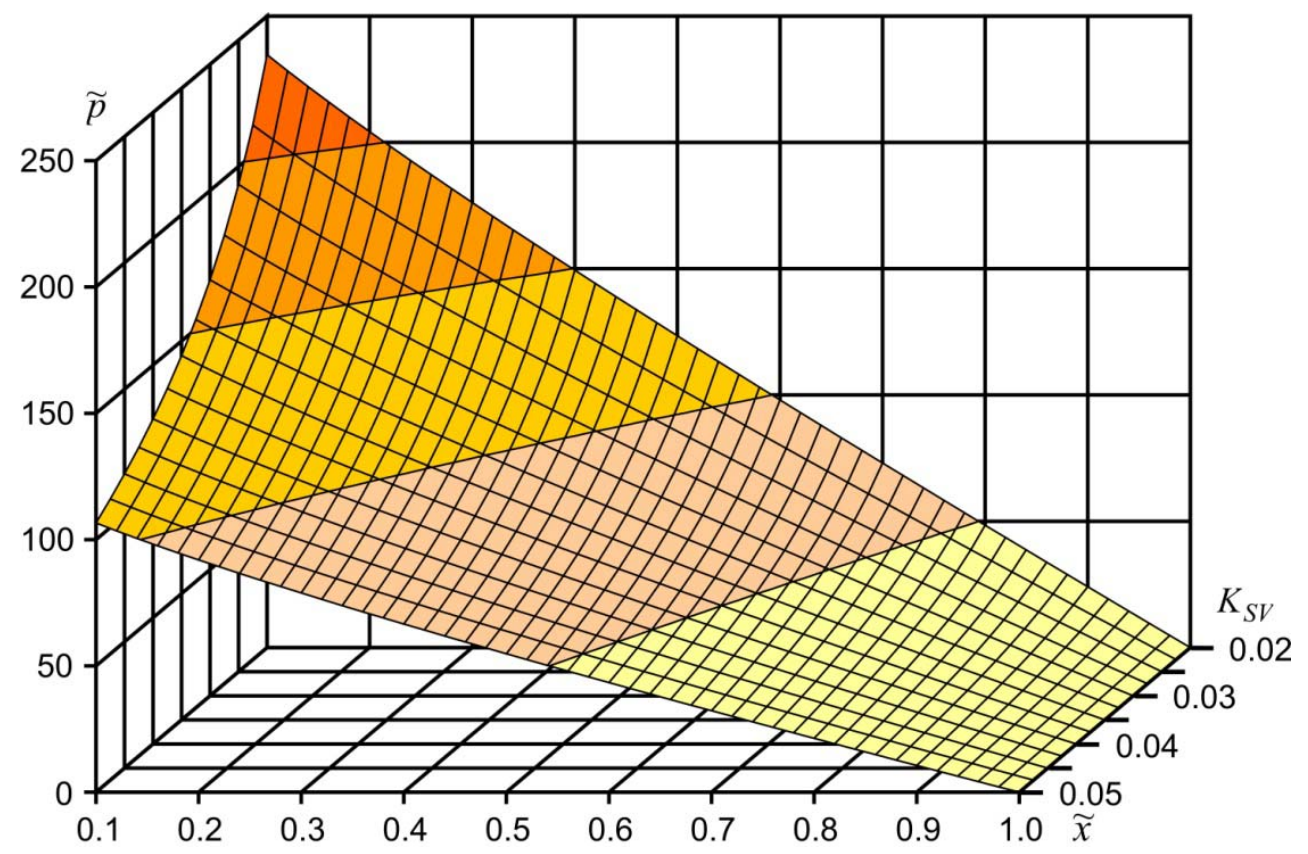

Fig.17. Dimensionless pressure distributions $\widetilde{p}$ for the Bingham ERF flow in a gap between parallel disks for different values of $K_{S V}=0.02 \div 0.05$, the value of exponent $n=1$ and constant value of $R_{\lambda}=0$. 


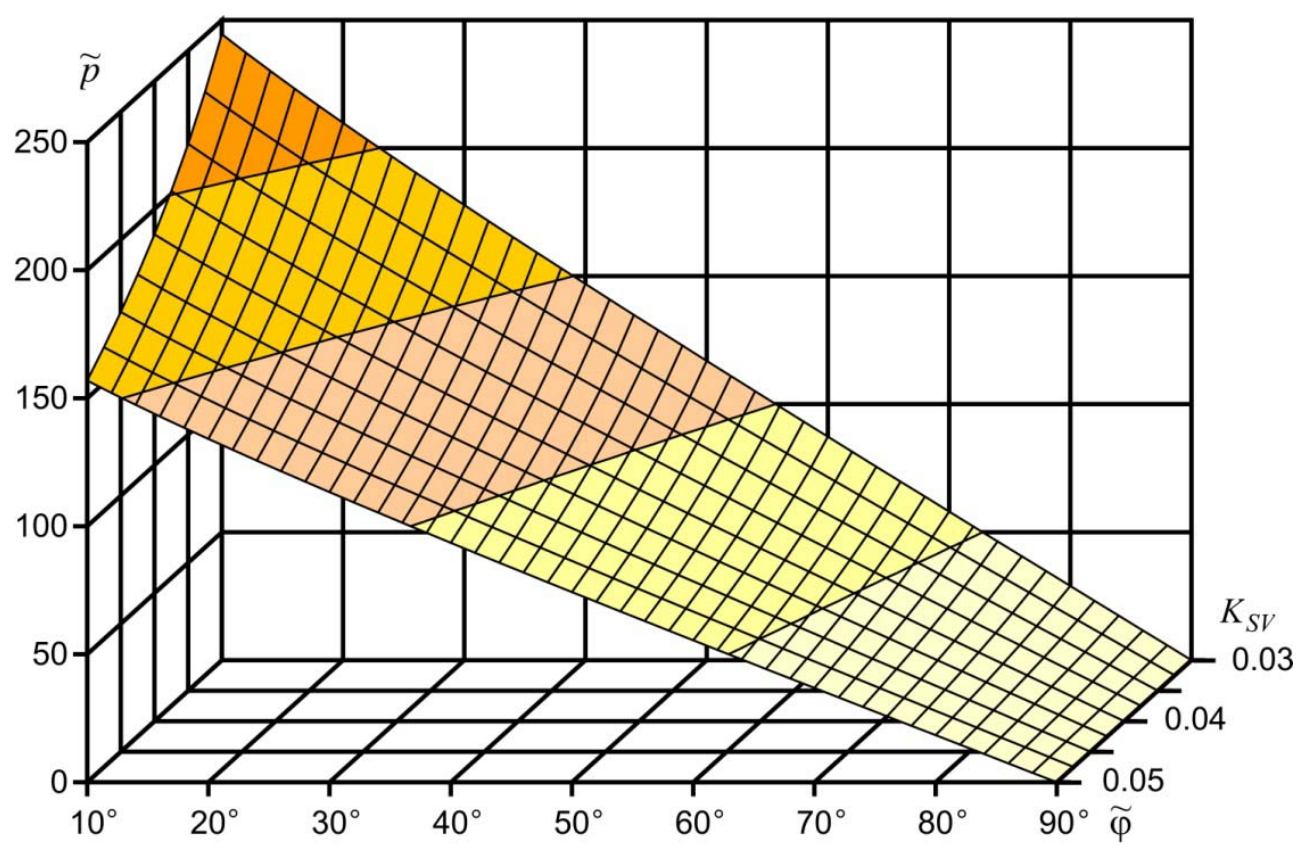

Fig.18. Dimensionless pressure distributions $\widetilde{p}$ for the Bingham ERF flow in a gap between concentric spherical surfaces for different values of $K_{S V}=0.03 \div 0.05$, the value of exponent $n=1$ and constant value of $R_{\lambda}=0$.

All dimensionless values of $K_{S V}$ and $R_{\lambda}$ that were used to illustrate graphically the presented results are taken from the experimental viscometric data for the ERFs of the Vočadlo type in slit flows [30, 31] and also from the analysis of the experimental results for the Vočadlo lubricant flows in thrust slide bearings [23].

\section{Conclusions}

In this paper, the relative inertia effect as a function of the Reynolds number was investigated in a clearance flow of an ERF of Vočadlo type between two surfaces of revolution. All these theoretical results were obtained by using the method of averaged inertia.

From the general considerations, formulae and graphs presented here for the Vočadlo ERF flow in a narrow gap of constant thickness between parallel disks and concentric spherical surfaces shown in Fig. 3 and Fig. 4 one may conclude that the pressure values:

- decrease with the increase of the modified Reynolds number $R_{\lambda}$,

- increase with the increase of the non-linearity index $n$,

- $\quad$ increase with the decrease of the de Saint-Venant ER number $K_{S V}$,

- $\quad$ are larger between concentric spherical surfaces than these ones between parallel disks for small values of $K_{S V}$,

- for large values of $K_{S V}$ it is inversely.

For small values of the de Saint-Venant ER number $K_{S V}$ the influence of the Reynolds number $R_{\lambda}$ on the pressure values is inconsiderable. Therefore, it may be considered that for these values of $K_{S V}$ the Vočadlo ER fluid flows without inertia effects. The pressure values are larger for the flows between concentric spherical surfaces than these for flows between parallel disks. 
Generally, it may be concluded for the Vočadlo ER fluid flows in the gap between two surfaces of revolution that the pressure values:

- $\quad$ are larger for the flow in the gaps with curvilinear generating lines than these for the flow in gaps with rectilinear generating lines.

Some general information about experimental data concerning the flows of ERFs of the Vočadlo type may be found in the studies carried out by Korobko [20] and Abu-Jdayil [38]. Korobko presented her experimental results in a graphic form and these results are generally similar to the present results without inertia.

\section{Nomenclature}

$A_{i}(n)$ - auxiliary function defined by formula (2.37)

$A_{n}$ - auxiliary function defined by formula $(2.32)_{1}$ or $(2.38)_{1}$, respectively

$D(x)$ - auxiliary function defined by formulae $(2.8)_{2},(2.31)$ and (2.36), respectively

$h$ - half of the fluid film thickness

$I_{(n)}^{(j)}$ - auxiliary function defined by formula $(2.38)_{3}$

$I_{(n)}^{(j ; \beta)} \quad$ - auxiliary function defined by formula $(2.32)_{3}$

$J_{(n)}^{(\alpha)}(x)$ - auxiliary function defined by formula $(2.38)_{2}$

$J_{(n)}^{(\alpha ; \beta)}(x)$ - auxiliary function defined by formula $(2.32)_{2}$

$K$ - plasticity number

$K_{S V}-$ de Saint-Venant ER plasticity number

$n$ - non-linearity index

$p$ - pressure

$Q$ - flow rate

$R, R(x)$ - local radius

$R_{i}$ - inlet radius to the gap

$R_{o}$ - outlet radius from the gap

$R_{\lambda}$ - modified Reynolds number

$S$ - signum function

$S(x)$ - auxiliary function defined by formulae $(2.8)_{1},(2.30),(2.33)$ and (2.35), respectively

$T_{y x}$ - component of the shear stress tensor

$U$ - applied voltage

$\mathrm{v}_{x}, \mathrm{v}_{y}$ - velocity components

$\alpha, \beta$ - ER experimental constants

$\rho-$ fluid density

$\varphi-$ central angle of spherical surface

$\tau$ - shear stress

$\tau_{0}-$ yield shear stress

\section{References}

[1] Winslow W.H. (1949): Induced fibration of suspensions. - J. Appl. Phys. vol.20, pp.1137-1140.

[2] Shulman Z.P., Gorodkin P.N., Korobko E.V. and Gleb V.K. (1981): The electrorheological effect and its possible uses. - J. Non-Newtonian Fluid Mech., vol.8, pp.29-41.

[3] Jordan T.C. and Show M.T. (1989): Electrorheology. - IEEE Trans on Electrical Insulations, vol.24, No.5, pp.849-878. 
[4] Dimarogonas A.D. and Kollias A. (1992): Electrorheological fluid-controlled smart journal bearings. - Tribology Transactions, vol.35, pp.611-618.

[5] Otsubo Y. (1992): Electrorheological properties of silica suspensions. - Journal of Rheology, vol.36, No.3, pp.479-496.

[6] Jung S.Y. and Choi S.-B. (1995): Analysis of a short squeeze-film damper operating with electrorheological fluids. - Tribology Transactions, vol.38, pp.857-862.

[7] Kobayashi K., Okamura K., Sakai T. and Sato M. (1996): Evaluation of the flow rate of an electro-rheological fluid (corn starch-kerosene) flowing through a narrow channel formed by a pair of electrodes. - Canadian J. Chem. Engng., vol.74, pp.394-398.

[8] Shulman Z.P. and Nosov V. (1996): Rotation of the axisymmetric dielectric bodies in electrorheological suspensions. - Int. J. Modern Phys., vol.10, pp.2903-2915.

[9] Walicki E. and Walicka A. (1995): Flow of a liquid metal in slots of casting dies. - Proc. of Nat. Conf. "Foundry 95" Kielce Solid Metals Alloys, vol.24, pp.155-164.

[10] Walicki E. and Walicka A. (1997): Throughflows of viscoplastic fluids between fixed surfaces of revolution. - Proc. of 5th Nat. Conf. on Multiphase Flows, vol.2, pp.133-136, Gdańsk.

[11] Walicki E. and Walicka A. (1998): Reynolds number effects in the flow of an electrorheological fluid between fixed surfaces of revolution. - J. Intelligent Mater. System Structures, vol.9, No.8, pp.662-666.

[12] Basavaraja J.S., Sharma S.C. and Jain S.C. (2010): a study of misaligned electrorheological fluid lubricated holeentry hybrid journal bearing. - Tribology International, vol.43, No.5-6, pp.1059-1064.

[13] El Wahed A.K. (2011): The influence of solid-phase concentration on the performance of electrorheological fluids in dynamic squeeze flow. - Materials \& Design, vol.32, No.3, pp.1420-1426.

[14] Lee D.Y. and Wereley N.M. (1999): Quasi-steady Herschel-Bulkley analysis of electro- and magneto-rheological flow mode dampers. - J. Intell. Mat. Systems Structures, vol.10, No.10, pp.761-769.

[15] S.R. Hong, S.-B. Choi and N.M. Wereley (2005): Non-dimensional analysis and design of a magnetorheological damper. - Journal of Sound and Vibration, vol.288, pp847-863.

[16] Hong S.R., Wereley N.M., Choi Y.-T. and Choi S.-B. (2008): Analytical and experimental validation of a nondimensional Bingham model of mixed-mode magnetorheological damper. - Journal of Sound and Vibration, vol.312, pp.399-417.

[17] Choi Y.-T., Cho J.-U., Choi S.-B. and Wereley N.M. (2005): Constitutive models of electrorheological and magnetorheological fluids using viscometers. - Smart Materials and Structures, vol.14, No.5, pp.1025-1036.

[18] Covey G.H. and Stanmore B.R. (1981): Use of the parallel-plate plastometer for the characterisation of viscous fluids with a yield stress. - J. Non-Newtonian Fluid Mech. vol.8, pp.249-260.

[19] Shulman Z.P. (1975): Convective Heat Transfer of Rheologically Complex Fluids. - (in Russian) Energy Moscow.

[20] Korobko E.V. (1996): Electrostructured (Electrorheological) Liquids: Singularities of the Hydrodynamics and Usabilities (in Russian). - Belarus Acad. Sci. Minsk.

[21] Vočadlo J. and Charles M.W. (1973): Characterization and laminar flow of fluid-like viscoplastic substances. - Can. J. Chem. Engng., vol.31, No.2, pp.116-121.

[22] Shen M., Cao J.G., Xue H.T., Huang J.P. and Zhou L.W. (2006): Structure of polydisperse electrorheological fluids: experiment and theory. - Chemical Physics Letters, vol.423, No.1-3, pp.165-169.

[23] Falicki J. (2007): The Influence of Viscoplastic Lubricants on the Pressure Distributions in the Thrust Slide Bearings. - [in Polish] PhD Thesis, University Press, Zielona Góra.

[24] Esmonde H., See H.H. and Swain M.V. (2009): Modelling of ER squeeze films at low amplitude oscilations. Journal of Non-Newtionian Fluid Mechanics, vol.161, No.1-3, pp.101-108.

[25] Sheng P. and Wen W. (2010): Electrorheology: statics and dynamics. - Solid State Communications, vol.150, No.21-22, pp.1023-1039.

[26] Barnes H.A. and Walters K. (1985): The yield stress myth. - Rheol. Acta, vol.24, pp.323-326. 
[27] Barnes H.A. (1999): The yield stress - a review or ' $\pi \alpha v \tau \alpha \rho \varepsilon$ ' - everything flows? - J. Non-Newtonian Fluid Mech., vol.81, pp.133-178.

[28] Corradini M.G. and Peleg M. (2005): Consistency of dispersed food systems and its evaluation by squeezing flow viscometry. - J. Text. Stud., vol.36, pp.605-629.

[29] Qiao Y. and Zhao X. (2009): electrorheological effect of carbonaceous materials with hierarchical porous structures. - Colloids and Surfaces A: Physicochemical and Engineering Aspects, vol.340, No.1-3, pp.33-39.

[30] Wunderlich Th. and Brunn P.O. (2000): Pressure drop measurements inside a flat channel - with flush mounted and protruding electrodes of variable length - using an electrorheological fluid. - Experiments in Fluids, vol.28, pp.455-461.

[31] Abu-Jdayil B., Asoud H. and Brunn P.O. (2007): Effect of polymer coating on the behavior of an electrorheological fluid in slit flow. - Materials and Design, vol.28, pp.928-940.

[32] Whittle M., Firoozian R., Bullough W.A. and Peel D.J. (1994): The pressure response in ER walve flow. J. Intelligent Mater. System Structures, vol.5, No.1, pp.105-111.

[33] Walicka A. (2002): Rheodynamics of Non-Newtonian Fluids Flow in Straight and Curved Channels (in Polish). Zielona Góra: University Press.

[34] Walicka A. (2002): Rotational Flows of the Rheologically Complex Media in Thin Annular Channels (in Russian). - Zielona Góra: University Press.

[35] Walicka A. (1999): Analysis of polymers flow through dies of forming devices. - Applied Mechanics and Engineering, vol.4, No.2, pp.341-361.

[36] Roussel N. (2001): Analyse des Écoulements des Fluides Homogènes Complexes et Plastiques Diphasiques: Application à L'essai de Compression Simple. - PhD Thesis, I. N. S. A., Rennes, France.

[37] Walicka A. and Falicki J. (2008): Inertia effects in thrust curvilinear hydrostatic bearing lubricated by a Vočadlo fluid. - International Journal of Applied Mechanics and Engineering, vol.13, No.3, pp.817-828.

[40] Abu-Jdayil B. (1996): Electrorheological Fluids in Rotational Couette Flow, Slit Flow and Torsional Flow (Clutch). - Shaker Publishing House, Aachen.

Received: March 13, 2017

Revised: May 24, 2017 